\title{
Life cycle assessment of two baby food packaging alternatives: glass jars vs. plastic pots
}

\author{
Sebastien Humbert • Vincent Rossi • Manuele Margni • \\ Olivier Jolliet • Yves Loerincik
}

Received: 21 August 2008 / Accepted: 28 November 2008 / Published online: 20 January 2009

(C) Springer-Verlag 2009

\begin{abstract}
Background, aim, and scope This paper compares the life cycle assessment (LCA) of two packaging alternatives used for baby food produced by Nestlé: plastic pot and glass jar. The study considers the environmental impacts associated with packaging systems used to provide one baby food meal in France, Spain, and Germany in 2007. In addition, alternate logistical scenarios are considered which are independent of the two packaging options. The $200-\mathrm{g}$ packaging size is selected as the basis for this study. Two other packaging sizes are assessed in the sensitivity analysis. Because results are intended to be disclosed to the public, this study underwent a critical review by an external panel of LCA experts.

Materials and methods The LCA is performed in accordance to the international standards ISO 14040 and ISO 14044. The packaging systems include the packaging production, the product assembly, the preservation process, the distribution, and the packaging end-of-life. The production of the content (before preservation process), as well as the use phase are not taken into account as they are considered not to change when changing packaging. The inventory is based on data obtained from the baby food producer and the suppliers, data from the scientific literature, and data from the ecoinvent database. Special care is taken to implement a system expansion approach for end-of-life open and closed loop recycling and energy production (ISO 14044). A comprehensive impact assessment is performed using two life cycle impact assessment
\end{abstract}

Responsible editor: Walter Klöpffer

S. Humbert $(\bowtie) \cdot$ V. Rossi $\cdot$ M. Margni $\cdot$ O. Jolliet $\cdot$ Y. Loerincik

Ecointesys-Life Cycle Systems Sàrl, PSE-A, EPFL,

CH-1015 Lausanne, Switzerland

e-mail: sebastien.humbert@ecointesys.ch methodologies: IMPACT 2002+ and CML 2001. An extensive uncertainty analysis using Monte Carlo as well as an extensive sensitivity study are performed on the inventory and the reference flows, respectively.

Results When looking at the impacts due to preservation process and packaging (considering identical distribution distances), we observe a small but significant environmental benefit of the plastic pot system over the glass jar system. Depending on the country, the impact is reduced by $14 \%$ to $27 \%$ for primary energy, $28 \%$ to $31 \%$ for global warming, $31 \%$ to $34 \%$ for respiratory inorganics, and $28 \%$ to $31 \%$ for terrestrial acidification/nutrification. The environmental benefit associated with the change in packaging mainly results from (a) production of plastic pot (including its end-of-life; $43 \%$ to $51 \%$ of total benefit), (b) lighter weight of packaging positively impacting transportation ( $20 \%$ to $35 \%$ of total benefit), and (c) new preservation process permitted by the plastic system $(23 \%$ to $34 \%$ of total benefit). The jar or pot (including cap or lid, cluster, stretch film, and label) represents approximately half of the life cycle impacts, the logistics approximately one fourth, and the rest (especially on-site energy, tray, and hood) one fourth.

Discussion The sensitivity analysis shows that assumptions made in the basic scenarios are rather conservative for plastic pots and that the conclusions for the 200-g packaging size also apply to other packaging sizes. The uncertainty analysis performed on the inventory for the German market situation shows that the plastic pot system has less impact than the glass jar system while considering similar distribution distances with a confidence level above $97 \%$ for most impact categories. There is opportunity for further improvement independent of the type of packaging used, such as by reducing distribution distances while still optimizing lot size. The validity of the main conclusions 
presented in this study is confirmed by results of both impact assessment methodologies IMPACT 2002+ and CML 2001.

Conclusions For identical transportation distances, the plastic pot system shows a small but significant reduction in environmental burden compared to the glass jar system. Recommendations and perspectives As food distribution plays an important role in the overall life cycle burdens and may vary between scenarios, it is important to avoid additional transportation of the packaged food in order to maintain or even improve the advantage of the plastic pot system. The present study focuses on the comparison of packaging systems and directly related consequences. It is recommended that further environmental optimization of the product also includes food manufacturing (before preservation process) and the supply chain of raw materials.

Keywords Baby food - Distribution · Glass $\cdot$ Jar $\cdot$ Life cycle assessment (LCA) · Packaging · Plastic · Polypropylene (PP) $\cdot$ Pot $\cdot$ System expansion $\cdot$ Uncertainty

\section{Background, aim, and scope}

The aim of this study is to assess the life cycle environmental impacts associated with two baby food packaging systems to be sold by Nestlé in France, Spain, and Germany: the glass jar and the plastic pot.

The study is intended to be of sufficient detail and quality to inform the public of the comparative impacts of these two choices. The latest methods on life cycle assessment (LCA) established in international standards (ISO 14040 and ISO 14044) are applied. The main results of this study (Rossi et al. 2007) are presented in this paper. The study was critically reviewed by a panel of four external LCA experts; the critical review report can be obtained by contacting the authors of the study.

\subsection{Current issues with LCA of packaging}

Packaging is one of the areas most intensively studied within the field of LCA and plays an especially important role in the case of food consumption (e.g., Hischier et al. 2005; Cordella et al. 2008; Mourad et al. 2008). However, most of the studies to date focus on inventory with few performing full impact assessment analysis or extensive uncertainty analysis. Furthermore, a system expansion to capture the impacts of end-of-life (Eriksson et al. 2005) is rarely systematically applied at all levels of the case study. Finally, rarely have studies been through a full critical review. In addition to practical results for a specific case study, the present study aims at addressing these common shortcomings.

\section{Methodology}

\subsection{Goal and scope}

The study considers the environmental impacts associated with packaging systems used to provide one baby food meal. The functional unit used as a basis for comparison between the two systems is to "provide a proper vehicle for a child's baby food meal in France, Spain, and Germany in 2007". The 200-g packaging size is selected as the basis for this study. Figures 1 and 2 present the glass jar and the plastic pot with the main reference flows, respectively.

Beyond the material and preservation process aspects, the study considers the entire packaging systems required to move the baby food from the point of production to the point of consumption. In particular, alternate logistical scenarios are considered to evaluate the influence of transportation distance on the study outcomes. An additional low-density polyethylene (LDPE) stretch film of approximately $0.25 \mathrm{~g}$ per jar or pot is used to wrap the whole pallet load during the distribution. Pallets are stacked in lorries according to capacity and national factors. The average number of 200 -g glass jars and plastic pots per lorry are 57,024 and 88,320 for France, 66,528 and 84,480 for Germany, and 71,280 and 91,200 for Spain, respectively.

The packaging systems include the package production, product assembly, distribution, and packaging fate at the end of its useful life (Fig. 3). Each of these life cycle phases includes a comprehensive assessment of the "cradle-tograve" requirements and burdens, including all quantifiable upstream processes.

Both systems are compared based on an equivalent functional unit. The systems' boundaries cover the same portion of their respective product life cycle and they share the same general architecture. The cut-off criteria are also identical.

The baby food, in its 2007 system with glass jars, is produced in Germany for the German and French markets and in Spain for the Spanish market. In the new system,

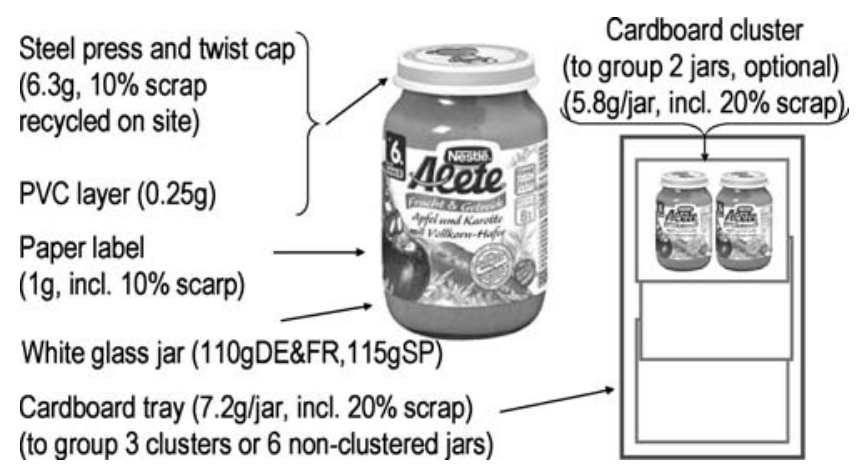

Fig. 1 Glass jar packaging and secondary components 


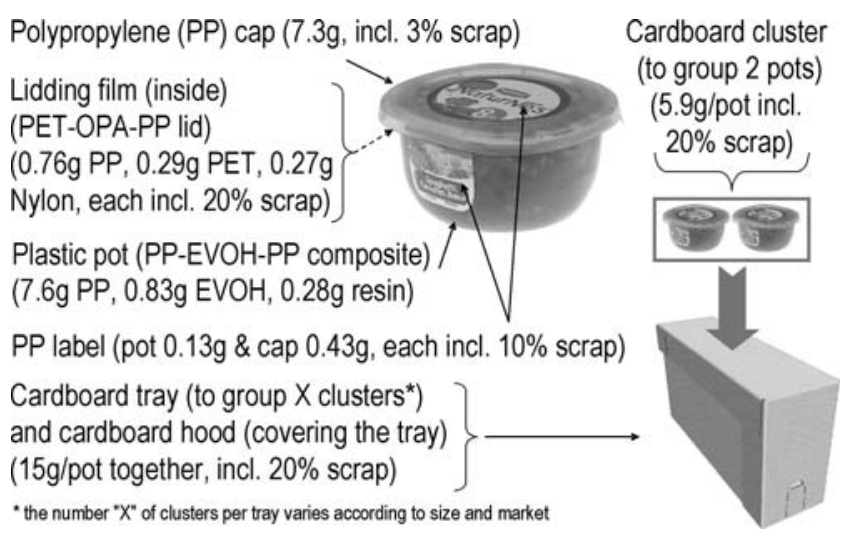

Fig. 2 Plastic pot packaging and secondary components

with plastic pots, it is expected to initially have one production site (in France).

\subsection{Life cycle inventory analysis}

Primary data and information are obtained from Nestlé and their suppliers. Secondary data are obtained from the scientific literature and the ecoinvent database (Frischknecht 2005; Frischknecht et al. 2005). Energy use, resource consumption, and pollutant emissions are quantified for each packaging system's life cycle.

Cut-off rules Cut-off criteria are used to decide whether processes shall be included in the product system and data gathered in the cases of (1) processes that are similar in both systems but slight differences exist and (2) processes and reference flows that are specific to one of the systems. In both cases, mass, primary energy, and environmental significance are used to make the decision. A cut-off level of $1 \%$ is applied (the process is neglected if it reaches less than $1 \%$ of the total known mass, primary energy, and impact, respectively), focusing on uncertain processes during use phase. All processes where data are available are taken into account, even if their contribution is less that $1 \%$. Therefore, the cut-off rule is used to avoid gathering unknown data, but not to neglect known data.

Food container production and all related processes are included. However, the baby food raw ingredient production is excluded, as it is present in the same quantities in all systems for a given packaging size. Processes needed for container assembly before, during, and after filling and sealing are considered when they present differences between the glass jar and the plastic pot systems. These processes include preservation (respectively, retort or ultrahigh temperature [UHT]), filling, sealing, labeling, handling, and packaging. Ancillary materials such as ink, glue, and colorants that fall below the cut-off criteria are only taken into account when included in a process used in the generic database. Processes excluded based on the $1 \%$ cut-off rule are: glue applied to paper labels on the glass jars, steel cap bending in order to give its shape, capital equipment, food preparation and cooking (prior to UHT process, in the case where UHT preservation is used), palletization, marketing, and administration (has a limited significance in materialbased applications; Rebitzer 2005). The distribution from production site to retailer (including transported food) is included. Infrastructure for distribution (warehouses) is excluded. Transport from retailer to private consumer is excluded-though representing more than $15 \%$ of the overall environmental impact of a packaging scenario (Rossi et al. 2007) - because no change in the consumer's shopping habits is expected with a change in the type of packaging. Usage by consumer is excluded. No refrigeration is needed during the distribution and the use phase. Heating of the food is excluded.

Energy The consumed natural gas is assumed to be of European mix, whereas national grid mixes are considered for the electricity. Table 1 presents the primary data collected at the baby food production sites.

Transport The transport for packaging supplies and product distribution is not managed by the baby food producer (Table 2). Therefore, generic data per ton kilometer provided by ecoinvent are adopted (lorry $40 \mathrm{t}$, average load of $9.68 \mathrm{t}$ ).

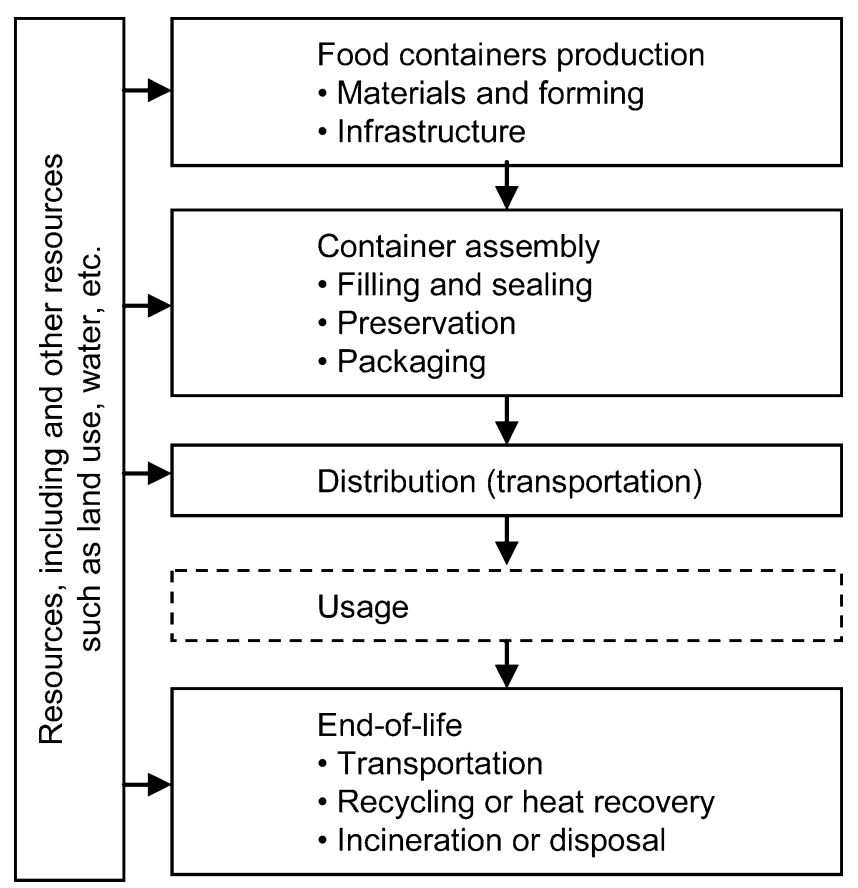

Fig. 3 System boundary for the baby food packaging systems 
Table 1 Primary data collected on the production sites (per ton of baby food processed; data from France are partly extrapolated from a factory in Germany)

\begin{tabular}{lcrr}
\hline & $\begin{array}{l}\text { Factory in Germany (for glass } \\
\text { jars in France and Germany) }\end{array}$ & $\begin{array}{l}\text { Factory in Spain (for } \\
\text { glass jars in Spain) }\end{array}$ & $\begin{array}{l}\text { Factory in France } \\
\text { (for all plastic pots) }\end{array}$ \\
\hline Electricity $(\mathrm{kWh})$ & 37 & 98 & 63 \\
Steam $(\mathrm{kg})$ & 560 & 519 & 275 \\
Water $\left(\mathrm{m}^{3}\right)$ & 6 & 6 & 6 \\
\hline
\end{tabular}

Distribution distance is calculated for most important distribution centers (weighted according to sales volume), covering the large majority of sales. When the repartition between jar and pot sizes is not known, the same average distance is used for all sizes. The average distance between distribution centers and retailers is assumed to be $250 \mathrm{~km}$ in all countries. In the current system (glass jars), average transportation distances to deliver the food in the respective markets (factory to retailer) are the following: $680 \mathrm{~km}$ in Germany, 1,010 km in Spain, and 1,880 km in France. For the plastic pots, the following distances are initially foreseen (factory to retailer): 1,250 km in Germany, 2,080 km in Spain, and 1,260 km in France. An intermediary scenario is also created in order to evaluate the sole influence of change in the preservation process and packaging, i.e., from glass jars to plastic pots, with no change in production location. The main reference flows related to the packaging of the glass jars and plastic pots are presented in Figs. 1 and 2, respectively.

End-of-life The end-of-life is analyzed using the system expansion principle, including all avoided burden as a function of recycling rates and end-of-life options (Figs. 4 and 5). System expansion is a method used to avoid coproduct allocation by expanding the boundary of the system investigated to include the alternative production of exported functions (e.g., Ekvall and Finnveden 2001; Cederberg and Stadig 2003; Moon et al. 2006). The material's end-of-life is analyzed according to national practices (Table 3 ).

Packaging waste generated at retailers (tray, hood, stretch film) is considered to be totally sent to recycling (tray and hood) or heat recovery channels (stretch film with $41 \mathrm{MJ} / \mathrm{kg}$ ). A recycling yield of $94 \%$ is used for tray and hood in order to account for material recycling losses. Six percent of the recycled share is, therefore, lost and joins the traditional waste treatment path indicated in Table 3 (landfilling and municipal waste incineration). Gross electric and thermal efficiency (LHV) for municipal waste incineration are $10 \%$ and $19 \%$ for Germany (Dehoust et al. 2002), $10 \%$ and $20 \%$ for Spain (estimate based on Doka 2003), and 5\% and $30 \%$ for France (Eco-Emballage, personal communication from Valérie Munoz 2007).

\subsection{Life cycle impact assessment}

The life cycle impact assessment is performed using the IMPACT 2002+ methodology (Jolliet et al. 2003). A sensitivity study is done using the CML 2001 methodology (Guinée et al. 2002).

\subsection{Sensitivity analysis, significant differences, and uncertainty analysis}

The important assumptions made in the study are tested in a sensitivity study to examine their influence on the overall outcomes. The sensitivity study tests the following issues: (1) the impact assessment methodology chosen, (2) the steam consumption at the production site, (3) the used packaging collection rate, (4) the efficiency of incinerators, (5) the polypropylene (PP) data consistency, (6) the production process for the ethylene-vinyl alcohol copolymer (EVOH) layer, (7) the recyclability of the PP-EVOHPP multilayer plastic cup, (8) the type of fuel substituted by polypropylene in steel or cement industry, and (9) the sensitivity of the findings to the $200-\mathrm{g}$ package size is tested for two other package sizes.
Table 2 Distances

(in kilometers) from packaging elements suppliers to the production site

\begin{tabular}{llll}
\hline & $\begin{array}{l}\text { Factory in Germany } \\
\text { (for glass jars) }\end{array}$ & $\begin{array}{l}\text { Factory in Spain } \\
\text { (for glass jars) }\end{array}$ & $\begin{array}{l}\text { Factory in France } \\
\text { (for plastic pots) }\end{array}$ \\
\hline Cluster & 318 & - & 494 \\
Glass jar/cup sheet & 417 & 581 & 472 \\
Label & 758 & 850 & 277 \\
Lidding film & - & - & 711 \\
Cap & 1,287 & 1,400 & 660 \\
Tray (+hood for pot) & 150 & 450 & 322 \\
Stretch LDPE Film & 566 & 332 & 400 \\
\hline
\end{tabular}


Fig. 4 System expansion for glass

Fig. 5 System expansion for plastics when polypropylene is recycled with a $40 \%$ rate

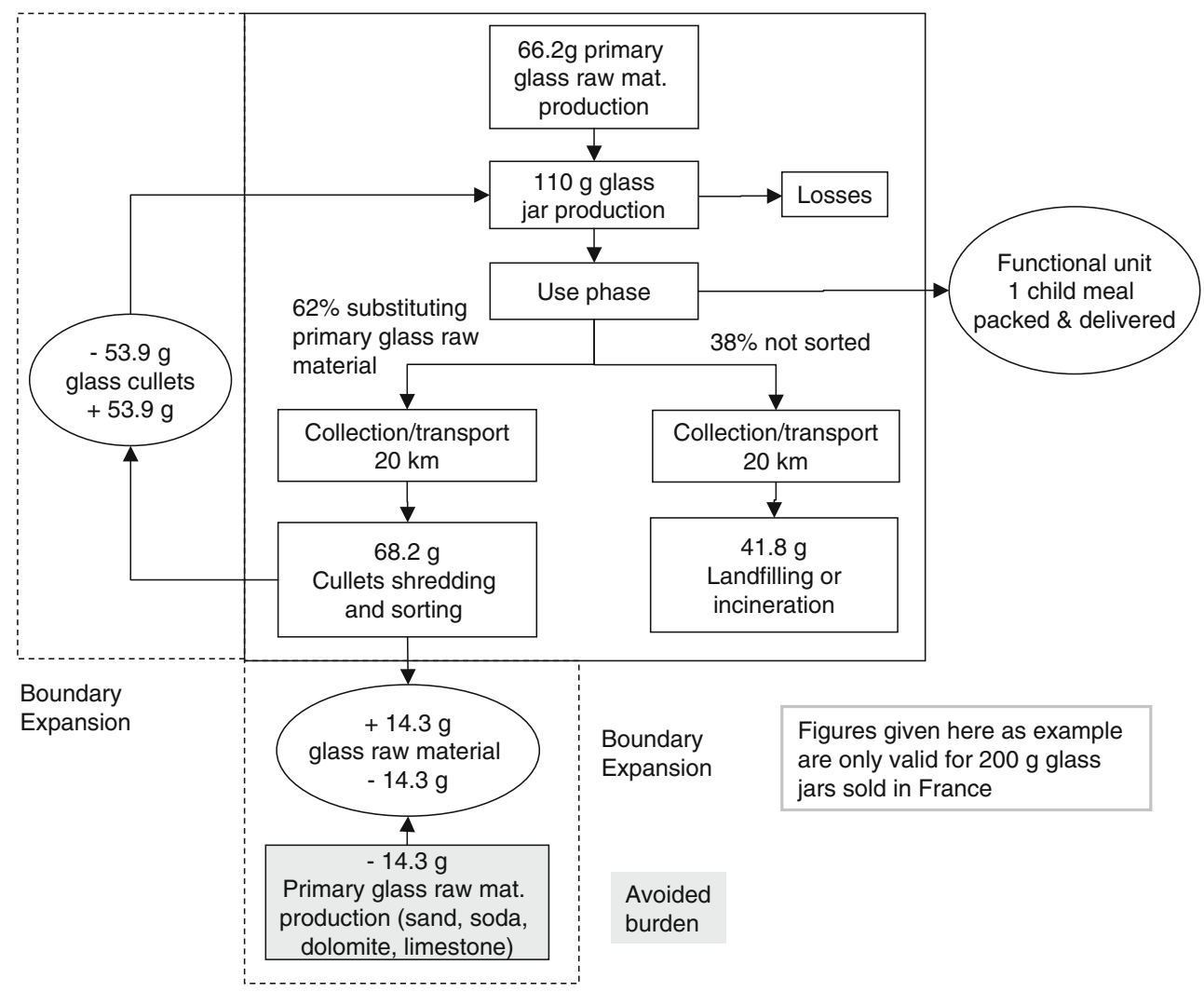


Table 3 End-of-life pathways for different materials for the three countries studied (period 2003-2006)

\begin{tabular}{llccc}
\hline Material & Pathway & Germany (\%) & Spain (\%) & France (\%) \\
\hline Glass & Recycled & 86 & 51 & 62 \\
& Incinerated & 14 & 4.9 & 20 \\
& Landfilled & 0 & 44 & 18 \\
Steel & Recycled & 84 & 56 & 55 \\
& Incinerated & 16 & 4.4 & 24 \\
& Landfilled & 0 & 40 & 22 \\
Polypropylene (LHV=39 MJ/kg) & Energy valorized & 75 & 26 & 0 \\
& Incinerated & 25 & 7.4 & 52 \\
& Landfilled & 0 & 67 & 48 \\
Cardboard(LHV=18 MJ/kg) & Recycled & 83 & 63 & 77 \\
& Energy valorized & 7.2 & 0 & 0 \\
& Incinerated & 10 & 3.7 & 12 \\
& Landfilled & 0 & 33 & 11 \\
\hline
\end{tabular}

For an initial discussion, any difference lower than $10 \%$ is not considered significant for the energy and global warming scores. The difference needs to be higher than $30 \%$ to be significant for respiratory inorganics or acidification and eutrophication. For the toxicity categories, an order of magnitude (factor 10) difference is typically required for a difference to be significant, especially if the dominant emissions are different between scenarios or are dominated by long-term emissions from landfill that can be highly uncertain. These criteria are commonly accepted in LCA. A more detailed analysis of parameter uncertainty propagation is carried out in Section 3.3 to check the robustness of these practices.

\section{Results and discussion}

\subsection{Life cycle inventory}

Water The total consumption of water varies between 4 and $5.5 \mathrm{~L}$ per jar or pot. However, uncertainties in water inventory of present databases do not allow determination of any significant difference between scenarios. Details and explanations on the intermediary flows and life cycle inventory results can be found in Rossi et al. (2007).

\subsection{Life cycle impact assessment}

Change in packaging (including preservation process) Figure 6 presents the impacts of the three scenarios in Germany for the 15 midpoint indicators of IMPACT 2002+. It shows that, for identical transport distances, the plastic pot system consistently has slightly but significantly lower impacts than the glass jar system $(30 \%$ in average in Germany, between 5\% and 90\%) with the exception of the ionizing radiation score. The ionizing radiation score is dominated by long-term radon-222 air emission. This emission is related to electricity consumption and plays a major role in every scenario where production of plastic pots occurs in France because of the nuclear-dominated electricity mix in this country. Since large uncertainties apply on long-term emissions, such as those found in

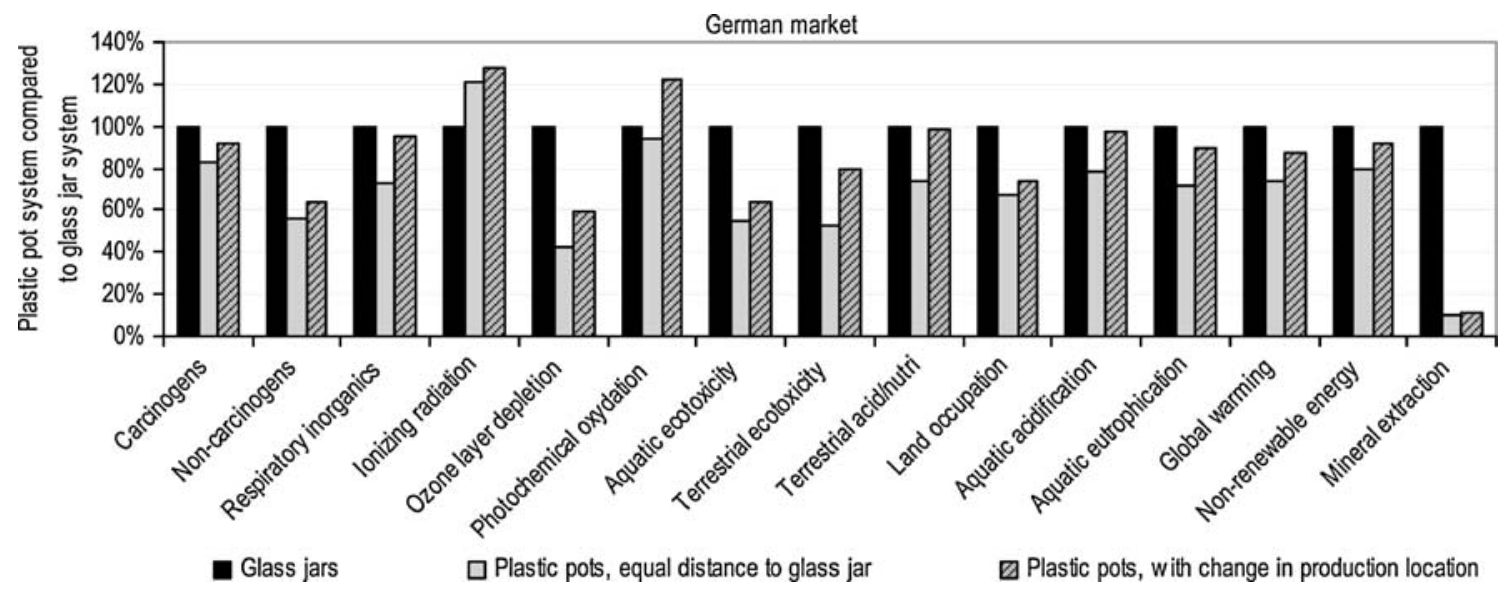

Fig. 6 Comparison of the 200-g glass jar system with the 200-g plastic pot system (without and with a change in the production location, respectively) for the German market for the 15 midpoint indicators of IMPACT 2002+ 
ionizing radiation, a difference of $50 \%$ on this indicator cannot be considered significant. The advantage of plastic remains for all countries (Fig. 7) when looking at the four impact categories having the higher importance to each of the four areas of protection (nonrenewable primary energy

\section{German market}
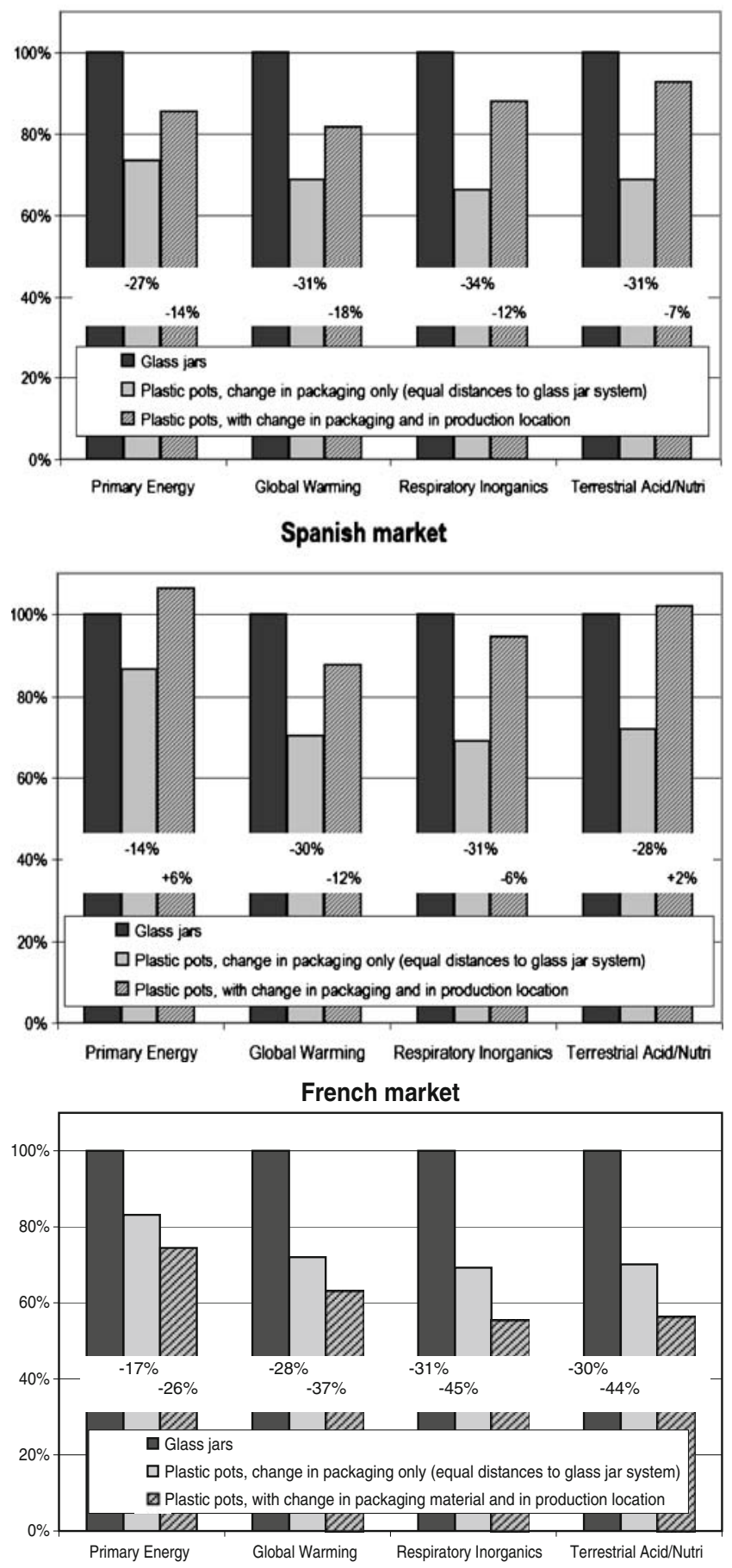

Fig. 7 Midpoint results for the four representative indicators, presented separately for each country for resources, global warming for climate change, respiratory inorganics for human health, and terrestrial acidification/ nutrification for ecosystem quality): The decrease in impact ranges from $14 \%$ to $27 \%$ for primary energy, $28 \%$ to $31 \%$ for global warming, $31 \%$ to $34 \%$ for respiratory inorganics, and $28 \%$ to $31 \%$ for terrestrial acidification/nutrification. This advantage of plastic pots is due to the sum of three effects, as shown in Fig. 8 and Table 4 that detail the contributions to global warming score: (a) production of plastic pot (including its end-of-life; $43 \%$ to $51 \%$ of total benefit), (b) reduction of mass to be distributed due to lighter packaging ( $20 \%$ to $35 \%$ of total benefit), and (c) new preservation process permitted by the plastic system with the UHT process leading to a limited on-site energy consumption ( $23 \%$ to $34 \%$ of total benefit). Figure 8 and Table 4 also show that the cap represents a significant fraction of the greenhouse gases emissions in the plastic pot systems ( $14 \%$ of total impact). The cardboard tray/ hood packaging has two to three times more impact in the plastic pot system than in the glass jar system due to a higher mass.

Change in production location If a change in the production location happens, transport distances may increase for the plastic pot system. In Germany, as indicated in Fig. 6, the environmental impact of the plastic pot system increases by $5 \%$ to $50 \%$. It still remains lower than the glass jars impacts in all categories with the exceptions of ionizing radiation and photochemical oxidation (which is dominated by traffic emissions). For Spain, Fig. 7 shows that a transportation increase partially offsets the advantage of plastic pots. In France, it is presently the glass jar distribution that leads to longer transport distances, resulting in a substantial difference between glass jar and plastic pot systems impacts.

\subsection{Uncertainty analysis}

An uncertainty analysis of the inventory for the representative case of Germany is performed using Monte Carlo statistical techniques. Currently, the uncertainty analysis can only be performed on the inventory since impact assessments methodologies implemented in SimaPro (PRé 2007) do not have uncertainty factors. Figure 9 presents the graphical results of the uncertainty analysis for the comparison between the glass jar system and the plastic pot system (without change in production location) in Germany for the 15 midpoint indicators of IMPACT 2002+.

Figure 9 shows that, for similar transport distances, the impacts of the plastic pot system are significantly lower than those of the glass jar system for all midpoint categories, except ionizing radiation. The level of statistical 


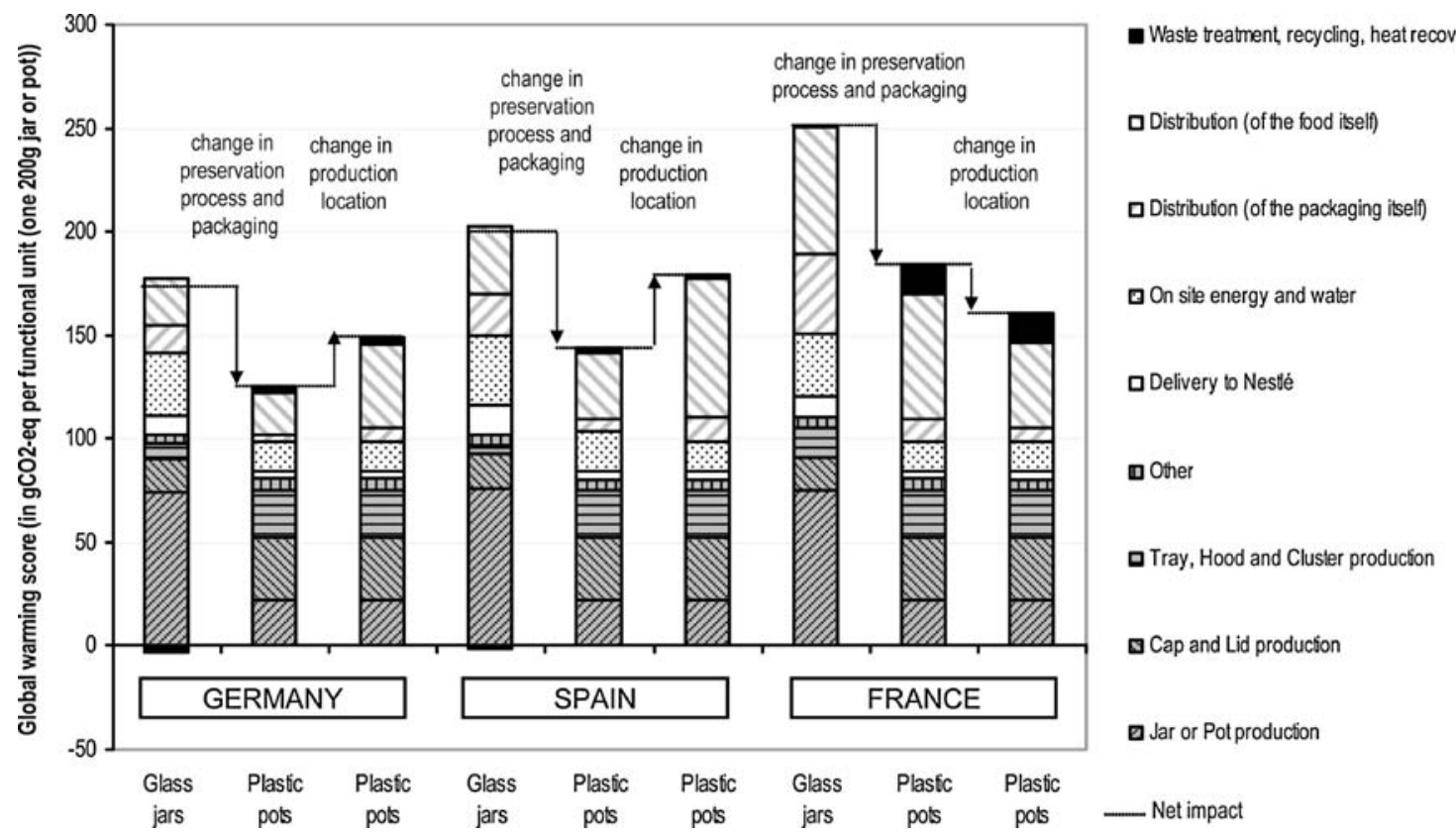

Fig. 8 Comparison of all nine 200-g scenarios for the global warming score

significance is higher than $97 \%$ for most categories and amounts to $94 \%$ for respiratory organics. However, when the location of production is changed, the level of significance is lower (between $80 \%$ and $100 \%$ ) due to the higher transport distances (see Rossi et al. 2007).

\subsection{Sensitivity analysis}

The following sensitivity studies are carried out on the 200-g packaging:

1. Impact assessment methodology chosen. Robustness of results is tested using CML 2001 (Guinée et al. 2002) and IMPACT 2002+ (Jolliet et al. 2003). CML 2001 leads to similar results for Germany, showing $20 \%$ to 95\% reduction in impact for the plastic pot system compared to the glass jar system with similar distribution distances. For Spain and France, most results are also similar to IMPACT 2002+. Main differences are related to aquatic ecotoxicity and eutrophication from long-term emissions from landfills of vanadium and COD, respectively, which are not considered significant.

2. Steam consumption at the production site. On-site steam consumption is varied by $\pm 30 \%$. Because the importance of steam consumption is higher for the glass jar system than for the plastic pot system, the former is more sensitive to the steam consumption (impacts up to $5 \%$ ) than the latter (up to $3 \%$ ). Though these variations do not inverse ranking in the scenarios, they need to be kept within the defined range for the plastic pot system to remain advantageous.
3. Used packaging collection rate. The results are tested using a separate collection rate reduced to half of the national average (see Table 3), applied to all packaging material recovered from households, but not to material recovered from retailers or other processing steps. Results show that, in France and Spain, the collection rate has less influence on the overall impacts than in Germany where recycling rates are higher and where the use of plastic as fuel substitute is dominant. Overall, lower households recycling rates increase impacts of the glass jar system in a larger proportion than for the plastic pot system.

4. Gross thermal and electric efficiency of incinerators. The gross thermal and electric efficiency of the municipal waste incinerators is reduced by half. The glass jar system is nearly unaffected since glass does not provide energy when incinerated. Only the plastic pot system in France and Germany is affected, showing an increase in potential environmental impact limited to about $3 \%$, which outweighs approximately $10 \%$ of the benefits obtained from the change in packaging. Because the municipal waste incineration rate is low in Spain, scenarios for this country are nearly unaffected.

5. Polypropylene data consistency. Life cycle inventory data from Plastic Europe (formerly APME) 1995 dataset (on which ecoinvent is partly based) is compared with the updated dataset of 2005 . The total primary energy decreases by only $2 \%$, while global warming emissions decrease by $4 \%$. Impacts on human health and ecosystems quality decrease substantiallydecreases of $70 \%$ for respiratory inorganics and $65 \%$ 
Int J Life Cycle Assess (2009) 14:95-106

103

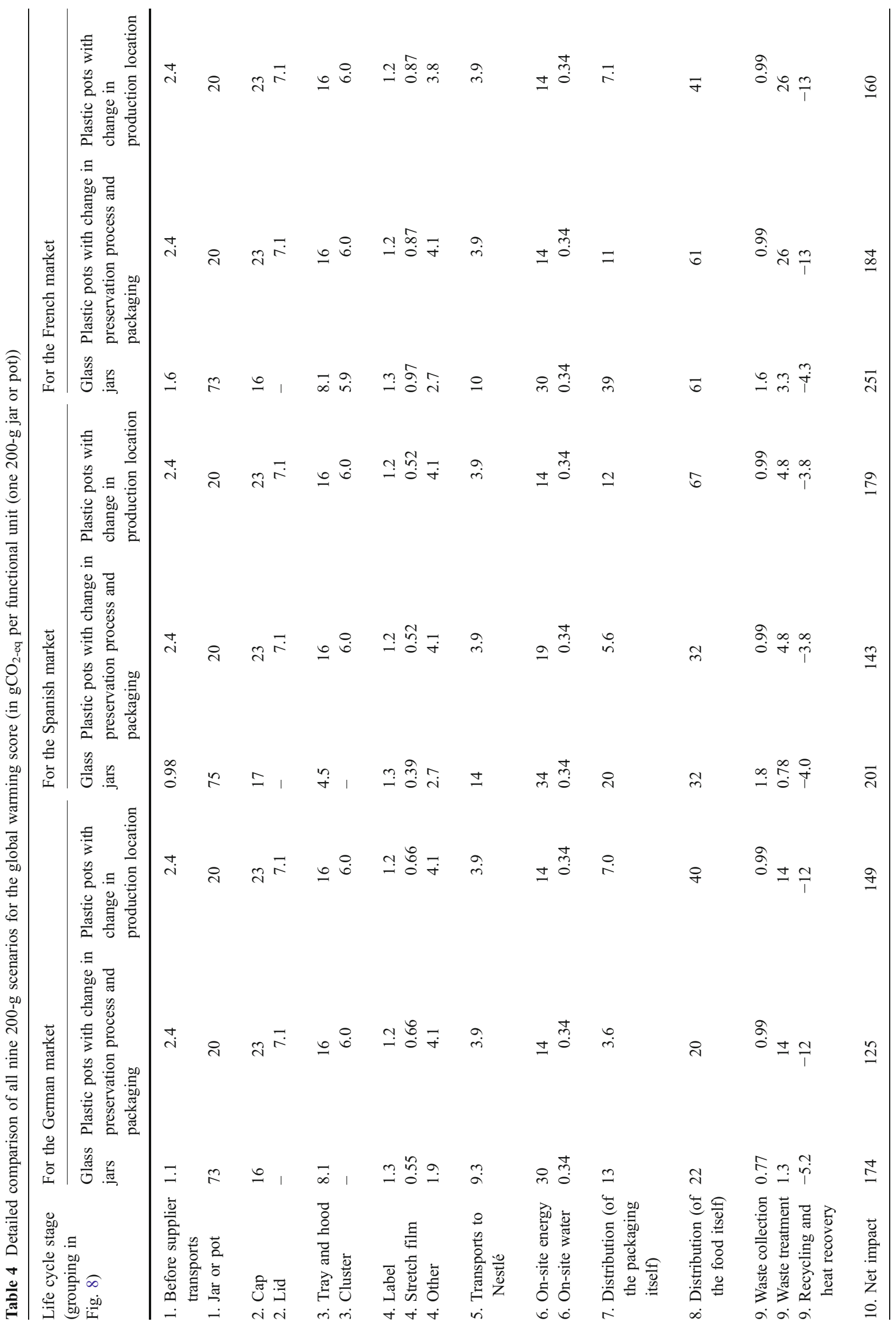

Springer 


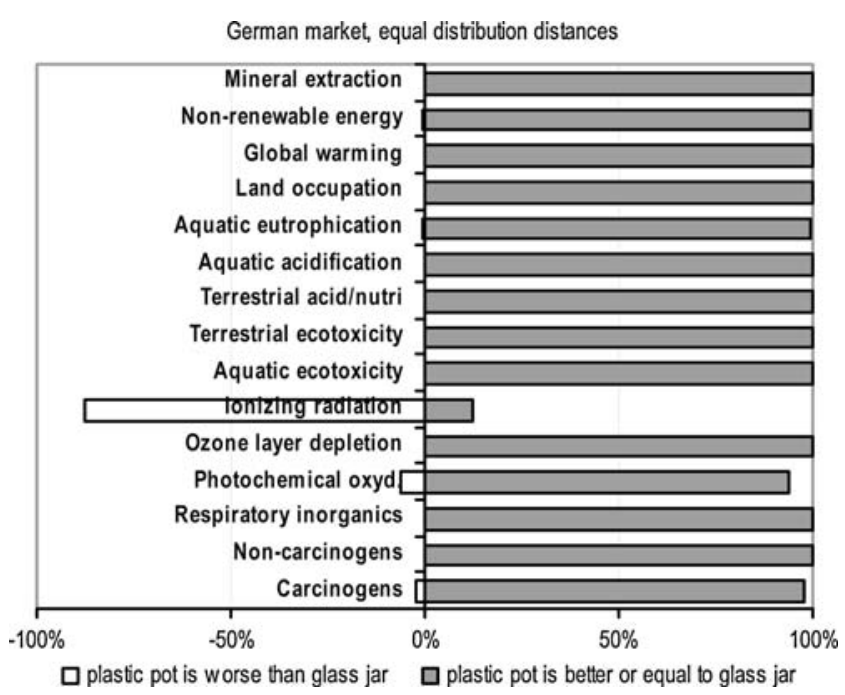

Fig. 9 Graphical results of the uncertainty analysis for the comparison between the glass system and the plastic system for similar distribution distances in the German market for the 15 midpoint indicators of IMPACT 2002+ (for each indicator, the white part of the bar represents the probability that the plastic pot is worse than the glass jar and the gray part of the bar represents the probability that the plastic pot is better than the glass jar)

for terrestrial acidification/nutrification impacts. Overall, the impact of the plastic pot system would be reduced between $2 \%$ and $45 \%$, depending on the category analyzed, compared to the results given under Section 3.2, thus increasing the environmental advantage of the plastic pot system over the glass jar system.

6. Importance of the production process for the EVOH layer. Ethylene vinyl acetate copolymer (EVA) data is used as a proxy for EVOH. EVOH is modeled using an upper bound - the plastic available in ecoinvent with the highest impacts - with emissions, heat waste, and unspecified hydrocarbons emissions to river and energy consumption three times higher than EVA. Results show that the changes are minor-well below cut-off criteria-indicating that using EVA as a proxy for EVOH is acceptable.

7. Recyclability of the PP-EVOH-PP multilayer cup of the plastic pots. The influence of the recyclability of the PP-EVOH-PP multilayer cup for the production of recycled PP material is tested using a recycling rate of $40 \%$ in Germany and $11 \%$ in Spain instead of $0 \%$ as assumed in the default results. There is no light packaging PP recycling in France; therefore, recyclability is not tested for this country. Results show that this amount of PP recycling brings a small environmental benefit. Recycling is only a little better than fuel substitution.

8. Type of fuel substituted by PP in steel or cement industry. When used in steel or cement industry, plastic is assumed to substitute the same amount of light fuel oil. When considering coal as the substituted fuel, the bonus for the plastic pot system increases and the total impact decreases by up to $40 \%$ in most categories. Thus, the assumption that light fuel oil is the substituted fuel is rather conservative for the plastic pot system since substituting coal leads to greater reduction in impact.

9. Other packaging sizes. When comparing the impacts for two other packaging sizes (one below $200 \mathrm{~g}$ and one above $200 \mathrm{~g}$, values undisclosed to the public) for the 15 midpoints indicators of IMPACT 2002+, one observes similar patterns between these two packaging sizes and the basic 200-g packaging size on which the study is conducted. Conclusions derived from the 200 -g scenarios can, therefore, be extended to all packaging sizes.

\subsection{Limitations}

The scope of the study and data availability also implies several limitations. The study focuses on the choice of packaging materials and its consequences, but does not cover food production, use phase, or improvement in food quality brought by plastic packaging. The impact assessment phase does not include noise and casualties. Water use results are provided, but are not evaluated with sufficient accuracy to enable any differentiation between scenarios over their whole life cycle.

\section{Conclusions and recommendations}

The present study covers the packaging systems as a whole, involving not only material and preservation process aspects, but also logistical aspects. This study is characterized by (a) the application of the system expansion principle, including all avoided burden as a function of recycling rates and end-of-life options, (b) the systematic quantification of life cycle impacts for each scenario for 15 impact categories, (c) an advanced uncertainty analysis applying Monte Carlo statistical techniques to the three German scenarios, and (d) a detailed sensitivity study to test results robustness in case of variations of the most uncertain data inputs.

\subsection{Conclusions}

When looking at the impacts due to preservation process and packaging (considering identical distribution distances), the plastic pot system in the scenario with the same 
transportation has a small but significant advantage over the glass jar system in all countries. The plastic pot system has $14 \%$ to $27 \%$ less primary energy, $28 \%$ to $31 \%$ less global warming, $31 \%$ to $34 \%$ less respiratory inorganics, and $28 \%$ to $31 \%$ less terrestrial acidification/nutrification than the glass jar system, depending on the country. Considering the impacts of production location change in addition to the impacts of preservation process and packaging change, the overall results show comparable set of environmental impacts for Spain ( $+6 \%$ to $-12 \%$, depending on the category), slight improvement for Germany $(-7 \%$ to $-18 \%)$, and net improvement for France $(-26 \%$ to $-45 \%)$.

The major factors responsible for the environmental benefit associated with the change in packaging are the following: (a) production and end-of-life of packaging: plastic pot has lower impacts than glass jar; (b) mass of the packaging: the lighter plastic packaging leads to an important reduction in packaging transportation; and (c) on-site preservation: the steam consumption is lower with the UHT process used in the plastic pot system than the retort process used in the glass jar system.

The sensitivity analysis clearly shows the importance of logistics. Indeed, there is opportunity for additional improvement through optimized distribution. The impact categories of respiratory inorganics and terrestrial acidification/nutrification are more sensitive to transportation distances than primary energy and global warming, as the substances that cause these impacts are emitted in higher proportions from transportation-related sources than from other sources. The sensitivity analysis shows that assumptions made for the basic scenario are in general rather conservative for the plastic pot system. For instance, considering a substitution of coal instead of light fuel oil, increasing the fraction of recycled plastic or considering the latest 2005 plastic data would provide additional advantages for the plastic pot system compared to the glass jar system. The sensitivity analysis shows that the conclusions for the 200-g packaging size also apply to other packaging sizes. Finally, the validity of the main conclusions is confirmed by results of both impact assessment methodologies IMPACT 2002+ and CML 2001.

\subsection{Recommendations}

It is recommended that further improvement steps on the new plastic pot system be performed. For example, alternate engineering of the plastic caps could be an opportunity in the performance of the plastic pot system. Considering the fact that the glass jar system had the opportunity to be improved over several decades, improvements on the new plastic pot may further increase its environmental benefits compared to the glass jar. Further efforts on heat saving or recovery on the production site could also lead to environmental and economic benefits. Finally, it is important to regularly evaluate the possibilities in improving the food distribution, which has a substantial effect on the environmental performance. The present study focuses on the comparison of packaging systems. Environmental optimization of the food production itself and supply chain is recommended to enable further improvements. The present results conform to the ISO 14040 and ISO 14044 standards and are suitable for public disclosure. The peer review report is available as an appendix of the detailed report (Rossi et al. 2007).

Acknowledgement The authors would like to thank Tanja Bernsdorf, Thomas Raedler, Peter Zahner, and Pascal Gréverath from Nestlé for their support in the conduct of this study, as well as the members of the critical review panel, Prof. Dr. Walter Kloepffer, Dr. Birgit Grahl, Dr. Pere Fullana, and Dr. Philippe Osset, whose useful critiques greatly helped improving this study.

\section{References}

Cederberg C, Stadig M (2003) System expansion and allocation in life cycle assessment of milk and beef production. Int J Life Cycle Assess 8(6):350-356

Cordella M, Tugnoli A, Spadoni G, Santarelli F, Zangrando T (2008) LCA of an Italian lager beer. Int J Life Cycle Assess 13(2):133139

Dehoust G, Gebhardt P, Gärtner S (2002) Der Beitrag der thermischen Abfallbehandlung zu Klimaschutz, Luftreinhaltung und Ressourcenschonung. Öko-Institut, Freiburg, Germany, April 2002

Doka G (2003) Life cycle inventories of waste treatment services, data v1.0. ecoinvent report no. 13, Swiss Centre for Life Cycle Inventories, Dübendorf, December 2003. Parts I, II and III

Ekvall T, Finnveden G (2001) Allocation in ISO 14041-a critical review. J Clean Prod 9:197-208

Eriksson O, Carlsson Reich M, Frostell B, Björklund A, Assefa G, Sundqvist J-O, Granath J, Baky A, Thyselius L (2005) Municipal solid waste management from a systems perspective. J Clean Prod 13:241-252

Frischknecht R (2005) Ecoinvent data v1.1: from heterogeneous databases to unified and transparent LCI data. Int J Life Cycle Assess 10(1):1-2

Frischknecht R, Jungbluth N, Althaus H-J, Doka G, Dones R, Heck T, Hellweg S, Hischier R, Nemecek T, Rebitzer G, Spielmann M (2005) The ecoinvent database: overview and methodological framework. Int J Life Cycle Assess 10(1):3-5

Guinée JB, Gorrée M, Heijungs R, Huppes G, Kleijn R, van Oers L, Wegener Sleeswijk A, Suh S, Udo de Haes HA, de Bruijn H, van Duin R, Huijbregts MAJ (2002) Life cycle assessment: an operational guide to the ISO standards. Kluwer, Dordrecht, The Netherlands

Hischier R, Althaus H-J, Werner F (2005) Developments in wood and packaging materials life cycle inventories in ecoinvent. Int J Life Cycle Assess 10(1):50-58 
Jolliet O, Margni M, Charles R, Humbert S, Payet J, Rebitzer G, Rosenbaum R (2003) IMPACT 2002+: a new life cycle impact assessment method. Int J Life Cycle Assess 8(6):324-330

Moon JM, Eun JH, Chung JS (2006) Allocation of process gases generated from integrated steelworks by an improved system expansion method. Int J Life Cycle Assess 11(4):247-253

Mourad AL, Garcia EEC, Vilela GB, von Zuben F (2008) Environmental effects from a recycling rate increase of cardboard of aseptic packaging system for milk using life cycle approach. Int J Life Cycle Assess 13(2):140-146
PRé (2007) SimaPro 7 LCA software. PRé Consultants, Amersfoort, The Netherlands

Rebitzer G (2005) Enhancing the application efficiency of life cycle assessment for industrial uses. Ph.D. dissertation, Faculté Environnement Naturel, Architectural et Construit, EPFL, Lausanne, Switzerland

Rossi V, Loerincik Y, Jolliet O (2007) Life Cycle Assessment of the new Nestlé LUCY Baby Food packaging: glass jars vs. plastic pots. Final Report. Available at http://www. ecointesys-lcs.ch 